\title{
Remove the water-induced traps toward improved performance in organic solar cells
}

\author{
Mumin Shi ${ }^{1}$, Tao Wang ${ }^{1}$, Rui Sun ${ }^{1}$, Qiang Wu ${ }^{1}$, Dandan $\mathrm{Pei}^{2}$, Hui Wang ${ }^{3}$, Wenyan Yang ${ }^{1}$, \\ Wei Wang ${ }^{1}$, Yao $\mathrm{Wu}^{1}$, Guohua Xie ${ }^{4}$, Tao Wang ${ }^{3}$, Long $\mathrm{Ye}^{2}$ and Jie Min ${ }^{1,5,6^{*}}$
}

\begin{abstract}
Clusters of water molecules have low ionization energies because of stabilization of charge from the dipole moment of surrounding molecules, and thus can form potential traps resulting in the undesirable photovoltaic performance in organic solar cells (OSCs). Herein, we demonstrated a solvent-water evaporation (SWE) strategy, which can effectively remove the water-induced traps that are omnipresent in photoactive layers, leading to a significant improvement in device performance. A higher power conversion efficiency of $\mathbf{1 7 . 1 0 \%}$ and a better device photostability are achieved by using this SWE method, as compared with the untreated binary PM6:Y6 system (15.83\%). We highlight the water-related traps as a limiting factor for carrier transport and extraction properties, and further reveal the good universality of the SWE strategy applied into OSCs. In addition, organic light-emitting diodes and organic field-effect transistors are investigated to demonstrate the applicability of this SWE approach. This strategy presents a major step forward for advancing the field of organic electronics.
\end{abstract}

Keywords: non-fullerene acceptor, water-induced traps, charge transport, device stability, organic semiconductors

\section{INTRODUCTION}

The promise of low-cost manufacturing, mechanical flexibility, colorful patterning and versatility in material synthesis makes organic solar cells (OSCs) very attractive as an important area of the renewable energy application [1-4]. Currently, single-junction OSCs have reached the milestone power conversion efficiencies (PCEs) of over $18 \%$ [1,5-7], approaching to the theoretically predicted record value $[1,8-10]$. The achievement of the milestone PCEs benefits from the innovations in the design and synthesis of p-type polymer donors and n-type nonfullerene acceptors (NFAs) [1,5,9,11-14]. However, seemingly rational and carefully argued molecular design guidelines, such as the use of heteroatom substitutions, weak non-covalent interactions and large $\pi$-conjugated central skeletons $[1,8,15,16]$, fail to result in the desired performance improvements. Often such non-ideal device performance, such as unbalanced charge transport properties, high non-geminate recombination losses or environmental degradation, is attributed to the factors mainly including twists and kinks in the polymer skeleton [17], remnant impurities acting as trap sites [18], contamination from solvents, the synthesis and processing conditions [19], or donor/acceptor (D/A) miscibility $[15,20]$. What is normally understated is, however, that environmental contaminants such as water $\left(\mathrm{H}_{2} \mathrm{O}\right)$, oxygen $\left(\mathrm{O}_{2}\right)$ and solvent species with tiny amounts of water can create discrete trap states and they may play a role in influencing the device performance. In particular, it was overlooked how the effects due to extrinsic species can mask more intrinsic structure-property correlations. For instance, water molecules or clusters have significantly low ionization energies and hence can form potential electron or hole traps [21,22], demonstrated by the recent results of electron-only and hole-only diodes made of several organic photovoltaic materials [21,23]. Also in OSCs, water molecules can either act as traps for charge carriers or cause redox reactions, but their influence on the photovoltaic performance is often ignored [24,25]. A

\footnotetext{
${ }^{1}$ The Institute for Advanced Studies, Wuhan University, Wuhan 430072, China

${ }^{2}$ School of Materials, Science and Engineering, Tianjin University, Tianjin 300072, China

${ }^{3}$ School of Materials Science and Engineering, Wuhan University of Technology, Wuhan 430070, China

${ }^{4}$ Hubei Key Lab on Organic and Polymeric Optoelectronic Materials, Department of Chemistry, Wuhan University, Wuhan 430072, China

${ }^{5}$ Beijing National Laboratory for Molecular Sciences, Beijing 100190, China

${ }^{6}$ Key Laboratory of Materials Processing and Mold (Zhengzhou University), Ministry of Education, Zhengzhou 450002, China

* Corresponding author (email: min.jie@whu.edu.cn)
} 
full analysis and fundamental understanding of how the presence of water-related traps affects the device performance have not been reported yet, which is an urgent need to solve this dilemma under current research trends and for future OSC applications.

It is well known that the presence in the active layer of charge carrier traps (e.g., water-induced defects)-localized state in the organic semiconductor material bandgap is a main factor that heavily deteriorates the corresponding performance parameters of organic light-emitting diodes (OLEDs) [26], organic field-effect transistors (OFETs) $[23,27,28]$, and sensors [23]. For instance, the unbalance of carrier mobilities caused by water-induced traps, which can be more likely to form the intermolecular voids in semiconductor films in OLEDs [22], can cause inevitable non-radiative recombination, thus reducing the quantum efficiency [29]. In addition, it has been demonstrated that water-related traps in semiconductor films are one of the main origins for inefficient transfer characteristics and bias stress instabilities in OFETs [28,30,31], even the reason for nonideal performance of new molecular designs. Apart from the above-mentioned fundamental understanding of water-related traps resulting from the ambient environment and processing solvents [21-23,26], some promising strategies such as the use of molecular additives [27,30,31], thermal annealing (TA) [32] and solvent vapor annealing (SVA) approaches [21] have been introduced to effectively remove the water molecules enclosed in nanoscopic voids in the thin films, and thus improve the device performance of organic semiconductor layers. Unlike the organic functional layers of organic electronics as mentioned above, the photoactive layers of organic photovoltaics are generally the bulk heterojunction $(\mathrm{BHJ})$ or layer-by-layer (LbL) architectures $[8,32-34]$. And the optimized BHJ and LbL blend morphologies, known as a thermally activated metastable state, can be easily tuned by the applications of solid and solvent additives, TA and SVA treatments $[8,19,35,36]$. Undoubtedly, these strategies can also negatively influence the nanoscale phase-separated blends [37-39], resulting in the undesired photovoltaic performance. It can be seen that the obtained photovoltaic performance is highly uncertain, which significantly limits the applications of the above-mentioned methods in OSCs. Of particular note is that a real approach of removing water molecules while maintaining the inherent morphology without loss of device performance has not been reported so far. Thus, finding an effective strategy to avoid water molecules into the blend morphology as much as possible is necessary, which will attract more attention from the scientific and industrial communities.

Herein, we focus our endeavor to solve this dilemma. We employed the commercially available polymer donor PM6 (poly[(2,6-(4,8-bis(5-(2-ethylhexyl-3fluoro)thiophen-2-yl)-benzo[1,2-b:4,5-b] dithiophene) $)$-alt- $\left(5,5\left(1^{\prime}, 3^{\prime}\right.\right.$ di-2-thienyl-5', $7^{\prime}$-bis(2-ethylhexyl)benzo $\left[1^{\prime}, 2^{\prime}-c: 4^{\prime}, 5^{\prime}-c^{\prime}\right]$ dithiophene-4,8-dione)]) [40] and non-fullerene small molecule acceptor Y6 ((2,2'-((2Z,2'Z)-((12,13-bis(2ethylhexyl)-3,9-diundecyl-12,13dihydro-[1,2,5] thiadiazolo $[3,4-e]$ thieno $\left[2^{\prime}, 3^{\prime}: 4^{\prime}, 5^{\prime}\right]$ thieno $\left[2^{\prime}, 3^{\prime}: 4,5\right]$ pyrrolo[3,2-g]thieno[ $\left[2^{\prime}, 3^{\prime}: 4,5\right]$ thieno[3,2- $\left.b\right]$ indole-2,10-diyl)bis(methanylylidene))bis(5,6-difluoro-3-oxo-2,3-dihydro- $1 \mathrm{H}$-indene2,1-diylidene))dimalononitrile)) [41] as the control $\mathrm{BHJ}$ system. Optimized binary PM6:Y6 devices show a high PCE of $15.83 \%$, which is comparable to the reported results $[5,6,40]$. Encouragingly, a promising strategy, namely solvent-water evaporation (SWE) approach, is developed, which can significantly avoid the presence of water molecules in the blend morphology and maintain its initial metastable microstructure while improving its charge transport and extraction properties, achieving a maximum PCE of $17.10 \%$ with a maximum fill factor (FF) of approximately 79\%. As compared with the control ones, this SWE-based morphology also possesses higher operational stability in inverted devices for $400 \mathrm{~h}$ lightsoaking. In particular, the unique advantage of SWE approach, which can play a dual role in removing water molecules in active layers while improving their device performance, was also confirmed in other four photovoltaic systems. Notably, we demonstrate that this SWE strategy as a simple and universal processing approach can also improve the device performance of the investigated OLEDs and OFETs.

\section{EXPERIMENTAL SECTION}

\section{Materials}

PM6 and J101 were synthesized by Wang T. Y6 and TBFT-TR were synthesized by $\mathrm{Wu} \mathrm{Y}$. Luo $\mathrm{Z}$ provided the MeIC. J71, PTB7-Th, ITIC and $\mathrm{PC}_{70} \mathrm{BM}$ were purchased from Solarmer Materials Inc. and used without further purification. Chloroform (CF) of analytical reagent (AR) grade was purchased from Sinopharm Chemical Reagent Beijing Co., Ltd and CF of HPLC grade was purchased from Solarmer Materials Inc.

Solvents (CF and chlorobenzene (CB)) were dried and distilled from appropriate drying agents prior to use. The processes of the purification of solvents are as followed: washing with water for several times to remove the ethanol, drying with potassium carbonate, refluxing with 
calcium chloride, and then distilling to remove the water molecules and achieve the anhydrous solvents. The distilled $\mathrm{CF}$ and $\mathrm{CB}$ were stored in the dark to avoid photochemical formation of phosgene.

\section{Device fabrication and testing}

Solar cells were fabricated in the configuration of the traditional sandwhich structure with an indium tin oxide (ITO) glass positive electrode and a perylene diimide functionalized with amino $\mathrm{N}$-oxide (PDINO)/aluminum (Al) negative electrode. The ITO-based substrates were pre-cleaned in an ultrasonic bath of detergent, deionized water, acetone and isopropanol, and ultraviolet (UV)treated in UV-ozone chamber (Jelight Company, USA) for $15 \mathrm{~min}$. A thin layer of PEDOT:PSS (poly(3,4-ethylene dioxythiophene):poly(styrene sulfonate)) (Baytron PVP Al 4083, Germany) was filtered through a $0.45-\mu \mathrm{m}$ poly (tetrafluoroethylene) (PTFE) filter and spin-coated at $3500 \mathrm{r} \mathrm{min}^{-1}$ for $30 \mathrm{~s}$ on the ITO substrate. Subsequently, PEDOT:PSS film was baked at $150^{\circ} \mathrm{C}$ for $15 \mathrm{~min}$ in the air, and the thickness of the PEDOT:PSS layer was approximately $40 \mathrm{~nm}$. The system PM6:Y6 $\left(16 \mathrm{mg} \mathrm{mL}^{-1}\right.$ in total, 1:1.2) was dissolved in CF (AR-CF and HPLC-CF) and 1-chloronaphthalene $(\mathrm{CN})$ with a concentraion of $0.5 \%$. Subsequently, a thin layer of PM6:Y6 blend was deposited through spin-coating at 2500-4000 $\mathrm{r} \mathrm{min}^{-1}$ for $30 \mathrm{~s}$ on the PEDOT:PSS layer and annealed at $110^{\circ} \mathrm{C}$ for $10 \mathrm{~min}$ in nitrogen glovebox. In addition, for the SVA and TA treatments, the above-mentioned samples were annealed by $55 \mu \mathrm{L}$ CF sovlent deposted into a glass dish with a diameter of $6 \mathrm{~cm}$, and on a $110^{\circ} \mathrm{C}$ hotplate for heating as a fucntion of annealing time. Notably, this SWE method was expressed in the main text. Besides, the system J101:ITIC $\left(16 \mathrm{mg} \mathrm{mL}^{-1}\right.$ in total, 1:1), J71:MeIC $\left(15 \mathrm{mg} \mathrm{mL}^{-1}\right.$ in total, 1:1) and TBFT-TR:PC ${ }_{70} \mathrm{BM}$ (14 $\mathrm{mg} \mathrm{mL}^{-1}$ in total, 1:0.8) were dissolved in HPLC-CF, PTB7-Th:PC ${ }_{70} \mathrm{BM}\left(25 \mathrm{mg} \mathrm{mL}^{-1}\right.$ in total, 1:1.5) was dissolved in $o$-dichlorobenzene (HPLC-ODCB) and all systems spin-cast onto the PEDOT:PSS layer. In addition to introducing anhydrous CF (HPLC grade) as processing solvent, in this strategy we firstly evaporated the CF solvent with small amounts of water molecules slowly stirred for twenty minutes in a snap-cap glass bottle at $110^{\circ} \mathrm{C}$ on a hot plate, and then added fresh CF solvent for the next step of film preparation. The thickness of the active layer was approximately $100 \mathrm{~nm}$ and the thickness of the photoactive layer was measured by a surface profiler (Alpha-Step 500, KLA-Tencor, USA). A PDINO layer via spining-coating a solution concentration of $1.0 \mathrm{mg} \mathrm{mL}^{-1}$ was deposited on the top of active layer.
Finally, the top $\mathrm{Al}$ electrode of $100 \mathrm{~nm}$ thickness was evaporated in vacuum onto the cathode buffer layer at a pressure of $5 \times 10^{-6} \mathrm{mbar}(1 \mathrm{mbar}=100 \mathrm{~Pa})$. The typical active area of the investigated devices was $4 \mathrm{~mm}^{2}$.

The current-voltage characteristics of the solar cells were measured under AM 1.5 G irradiation on an Enli Solar simulator $\left(100 \mathrm{~mW} \mathrm{~cm}^{-2}\right)$. Before each test, the solar simulator was calibrated with a standard singlecrystal Si solar cell (made by Enli Technology Co., Ltd., calibrated by the National Institute of Metrology (NIM) of China). Short circuit currents under AM 1.5 G $\left(100 \mathrm{~mW} \mathrm{~cm}^{-2}\right)$ conditions were estimated from the spectral response and convolution with the solar spectrum. The external quantum efficiency (EQE) was measured by a Solar Cell Spectral Response Measurement System QE-R3011 (Enli Technology Co., Ltd.). A calibrated silicon detector was used to determine the absolute photosensitivity at different wavelengths.

Stability measurements: We performed the long-time light stability of PM6:Y6 system for $400 \mathrm{~h}$ in this study. To insight the long-time stability of this device, we conducted the device structure of ITO/ZnO/active layer/ $\mathrm{MoO}_{3} / \mathrm{Ag}$. The solar cells were fabricated in a glovebox and aged under high vacuum, excluding the well-known effects of oxygen degradation from our experiments. The stability test was carried out under open-circuit conditions. The devices were not encapsulated.

OLED devices were fabricated on pre-patterned ITO substrates. The ITO-based substrates were pre-cleaned in an ultrasonic bath of detergent, deionized water, acetone and isopropanol, and UV-treated in UV-ozone chamber (Jelight Company, USA) for $15 \mathrm{~min}$. A thin layer of PEDOT:PSS (Baytron PVP Al 4083, Germany) was filtered through a $0.45-\mu \mathrm{m}$ PTFE filter and spin-coated at $3500 \mathrm{r} \mathrm{min}^{-1}$ for $30 \mathrm{~s}$ on the ITO substrate. Subsequently, PEDOT:PSS film was baked at $150^{\circ} \mathrm{C}$ for $15 \mathrm{~min}$ in the air, and the thickness of the PEDOT:PSS layer was approximately $40 \mathrm{~nm}$. The super yellow poly(phenylenevinylene) (SY-PPY, $5 \mathrm{mg} \mathrm{mL}^{-1}$ in total) was dissolved in $\mathrm{CB}$ and spin-cast onto the PEDOT:PSS layer. Then a methanol solution of poly[[2,7-bis(2-ethylhexyl)-1,2,3,6,7,8hexahydro-1,3,6,8-tetraoxobenzo[lmn] [3,8]phenanthroline-4,9-diyl]-2,5-thiophenediyl[9,9-bis [ $3^{\prime}((N, N$-dimethyl)- $\mathrm{N}$-ethylammonium)] propyl]-9H-fluorene-2,7diyl]-2,5-thiophenediyl] (PNDIT-F3N-Br) at a concentration of $1.0 \mathrm{mg} \mathrm{mL}^{-1}$ was blade-coated onto the active layer at $3500 \mathrm{r} \mathrm{min}^{-1}$ for $30 \mathrm{~s}$. To complete the fabrication of the devices, $100 \mathrm{~nm}$ of $\mathrm{Al}$ was thermally evaporated through a mask under a vacuum of $5 \times 10^{-6}$ mbar. 
OFET devices were fabricated by top gate/bottom contact (TGBC) structures. Source (S) and drain (D) electrodes were patterned on a glass substrate by photolithography and deposited onto the substrate through thermal evaporation. Electrodes were photo lithographically patterned to have $10-50$ and $1000 \mu \mathrm{m}$ channel length and width, respectively. $\mathrm{FeCl}_{3}(3 \mathrm{~nm})$ was thermally evaporated as the hole injecting layer on the cleaned substrates. PDPP2TBT $\left(5 \mathrm{mg} \mathrm{mL}^{-1}\right)$ solutions in CF were spin coated onto the $S / D$ patterned substrate and annealed at $250^{\circ} \mathrm{C}$ for $30 \mathrm{~min}$ in a $\mathrm{N}_{2}$ purged glove box. Poly(methyl methacrylate) (PMMA) $\left(80 \mathrm{mg} \mathrm{mL}^{-1}\right.$ in $n$ butyl acetate) was spin-coated as the gate dielectric at $2000 \mathrm{r} \mathrm{min}^{-1}$ for $60 \mathrm{~s}$ and annealed at $80^{\circ} \mathrm{C}$ for $2 \mathrm{~h}$ in a $\mathrm{N}_{2}$-purged glove box. The PMMA dielectric layer thickness was $\sim 500 \mathrm{~nm}$. Device fabrication was completed by thermally evaporating $50 \mathrm{~nm} \mathrm{Al}$ as the gate electrode using a metal shadow mask.

\section{Instruments and characterization}

Space charge limited current (SCLC) measurements Single carrier devices were fabricated and the dark current-voltage characteristics were measured and analyzed in the SCLC regime following the Ref. [1]. The structure of hole-only devices was glass/ITO/PEDOT:PSS/active layer $/ \mathrm{MoO}_{3}(10 \mathrm{~nm}) / \mathrm{Ag}(100 \mathrm{~nm})$. For the electron-only devices, the structure was glass/ITO/ZnO/active layer/ PDINO/Al (100 nm), where both $\mathrm{Al}$ and Ag were evaporated. Mobilities were extracted by fitting the current density-voltage curves using the Mott-Gurney relationship. The reported mobility data are average values over six devices of each sample.

\section{Photo-induced charge carrier extraction by linearly} increasing the voltage (photo-CELIV) measurements The investigated solar cells are illuminated with a 405-nm laser diode. A fast electrical switch was applied to isolate the device in order to prevent carrier extraction or sweep out. After the variable delay time, the switch connected the device to a function generator. In addition, current transients were recorded across the internal $50 \Omega$ resistor of our oscilloscope. To investigate the carrier mobility in the corresponding devices, the photo-CELIV curves were conducted using different experimental conditions, differing in delay time.

Transient photovoltage (TPV) measurements

For TPV measurements, devices were directly connected to an oscilloscope in open-circuit conditions (1 M $\Omega$ ). Then the device was illuminated with a white light LED at different light intensities. A small optical perturbation was applied using a 405-nm laser diode which was adjusted in light intensity to produce a voltage perturbation of $\Delta V_{\mathrm{o}}<10 \mathrm{mV} \quad V_{\text {oc }}$ (open-circuit voltage). The amount of charges generated by the pulse was obtained by integrating a photocurrent measurement $(50 \Omega)$ without bias light.

\section{Charge extraction (CE) measurements}

$\mathrm{CE}$ measurements can be used to determine the charge density in the active layer of the device at any point in the current density-voltage $(J-V)$ curve. The devices were held at a specified voltage in the dark or under illumination. At a certain time $t_{0}$, the light was switched off, the cell was switched to short-circuit conditions, and the resulting current transient was recorded with an oscilloscope. Most of the charge was extracted in a few microseconds due to a high internal electrical field at short circuit conditions. In addition, a fast analog switch from Texas Instruments (TS5A23159) was used to perform the switching from the specified voltage to short circuit conditions. It provided a very quick switching time (50 ns), a low on-state resistance $(1 \Omega)$, high off-state resistance $(>1 \mathrm{M} \Omega)$ and a very low charge injection $\left(<<10^{15} \mathrm{~cm}^{2} \mathrm{~V}^{-1} \mathrm{~s}^{-1}\right)$. A Keithley 2440 source-measurement unit was used to set the initial device voltage.

\section{Transient photocurrent (TPC) measurements}

Relevant solar cells were excited with a 405-nm laser diode. The TPC response of the devices was recorded at a short circuit condition to a $200 \mathrm{~s}$ square pulse from the LED with no background illumination. The current traces were recorded on a Tektronix DPO3034 digital oscilloscope by measuring the voltage drop over a $5-\Omega$ sensor resistor in series with the solar cell. A direct-current (DC) voltage was applied to the solar cell with an MRF544 bipolar junction transistor in common collector amplifier configuration.

\section{Capacitance spectroscopy Characterizations}

Capacitance measurements were performed using a ModuLab XM electrochemical workstation (AMETEK, UK) under a series of voltages with the amplitude of $60 \mathrm{mV}$ from $1 \mathrm{MHz}$ to $10,000 \mathrm{~Hz}$ under one AM $1.5 \mathrm{G}$ illumination conditions and in the dark.

\section{RESULTS AND DISCUSSION}

\section{Photovoltaic performance based on various film formation strategies}

The presence of water in various guises in photovoltaic 
materials has been suggested to be traps [21], which have thus far been related to impurities remaining from the synthesis, reception from the moisture environment and/ or contamination from the common organic solvents. In this study we firstly investigated the effects of waterrelated traps on the photoelectric properties of OSCs. In parallel, we also addressed the question what is the right way to effectively reduce the water-related trap concentration of the photoactive layers and simultaneously enhance their bulk charge transport properties and device efficiencies. The device structure is based on the configuration consisting of an ITO/PEDOT:PSS/PM6:Y6/PDI$\mathrm{NO} / \mathrm{Al}$. The details of device fabrication procedures are described in the EXPERIMENTAL SECTION. The PM6: Y6 photoactive layers were spun from various processing conditions and subsequently annealed for only $20 \mathrm{~min}$ to remove the residual CF solvent in the photoactive layers.

In order to determine the effects of water molecules in common solvents on device performance, we studied the photovoltaic performance of PM6:Y6 devices using two types of CF solvents for the film formation (Fig. 1b), including AR grade CF (AR-CF; assay percent range, $\geq 99.0 \%$ ) and HPLC grade CF (HPLC-CF; assay percent range, $\geq 99.8 \%$ ). The $J-V$ curves of the corresponding best-performing OSCs are plotted in Fig. 1c, and the detailed photovoltaic parameters are summarized in $\mathrm{Ta}$ ble 1 . As was expected to use the AR-CF solvent containing a tiny bit of dissolved water, the optimized PM6: Y6 device obtained a poor PCE of $15.25 \%$ with an $V_{\text {oc }}$ of $833 \mathrm{mV}$, a short-circuit current density $\left(J_{\mathrm{sc}}\right)$ of $25.39 \mathrm{~mA} \mathrm{~cm}^{-2}$, and a low FF of $72.11 \%$. Based on the same optimized process conditions (Fig. S1 and Table S1), the relevant device processed with HPLC-CF exhibits an enhanced PCE of $15.83 \%$, which is comparable to the results of Refs $[5,6,40]$. The $V_{o c}$ and $J_{s c}$ values remain almost unchanged at $833 \mathrm{mV}$ and $25.41 \mathrm{~mA} \mathrm{~cm}^{-2}$, respectively. The FF is slightly increased to $74.79 \%$. Since these two types of devices were fabricated by the same material batches and preparation processes, the poor performance of the AR-CF-processed devices is obviously due to the high sensitivity of the interaction between photovoltaic materials and water molecules. To further clarify the SWE effect on the blend morphological characteristics and device performance, we conducted twodimensional grazing-incidence wide-angle X-ray scattering (GIWAXS) measurements, as presented in Fig. S2. Obvious (010) diffractions located at $q_{\mathrm{z}}=1.750 \AA^{-1}$ were observed in these three PM6:Y6 blends, and their crystallite correlation lengths (CCLs) in the out-of-plane (OOP) direction are comparable, as provided in Fig. S2e and Table S2. Moreover, these three blends also showed similar diffractions in the in-plane (IP) direction (see Fig. S2f and Table S3). It should be noted that although it is very difficult to exclude that there are not in fact subtle differences in blend microstructure that could provide an explanation for the observed low performance of the ARCF devices, we would like to offer here a tentative, alternative explanation within the framework of waterinduced traps. It is also because that the statistical photovoltaic metrics and PCE histograms directly demonstrate the influence of water-related traps on device performance, as depicted in Fig. $1 \mathrm{~d}$.

In previous studies $[21,27,30,31]$, some strategies, including SVA and TA methods as well as solvent and solid additives, have been demonstrated to remove the (majority of) water-filled nanovoids acting as generic charge trap in organic semiconductors [21], improve the charge transport properties and/or lead to a significant improvement in OFET and OLED performance [27,30,31]. In order to remove the water molecule clusters and improve the device efficiencies, we also tried to use these approaches for the OSC fabrication. However, the implementation of these strategies caused great morphological evolutions, resulting in the reduced photovoltaic parameters, as exhibited in Figs S3 and S4. The SVA- and TA-treated PM6:Y6 active layers (15.47\% for SVA-treated blend for $60 \mathrm{~s}$ and $15.77 \%$ for TA-treated blend for 5-10 min) exhibit the slightly lower device efficiencies than those of the control devices (15.83\%), even though there may be fewer water-related traps in the treated blends. Further extending the TA and SVA time, the $J_{\mathrm{sc}}$ and FF values as well as the PCEs decreased gradually (Tables S3 and S4). Of note is that the performance difference of OFET and OSC devices is mainly associated to the TA and SVA treatments investigated in this work, which possess high susceptibility to interact with BHJ blend microstructure $[19,36]$. As shown in Fig. S5, we also conducted the GIWAXS measurements of the blends without and with the SVA and TA post-treatments. And the calculated results of the $q_{\mathrm{xy}}$ direction (IP, $q_{\mathrm{xy}}=$ $0.296 \AA^{-1}$ ) and $q_{\mathrm{z}}$ direction (OOP, $q_{\mathrm{z}}=1.750 \AA^{-1}$ ) are summarized in Table S5. The (100) peaks in the $q_{\mathrm{xy}}$ direction in the SVA- and TA-treated are more intense than that for the HPLC-CF casted active layer, indicating that the molecular stacking order of Y6. In the meanwhile, obvious (010) diffractions located at $q_{\mathrm{z}}=1.750 \AA^{-1}$ were observed in these three blends, and the strength was improved in the SVA- and TA-treated blends. The CCLs of $\pi-\pi$ scattering were increased from $27.54 \AA$ for the HPLC-CF casted blend to $28.94 \AA$ for the SVA-treated 
a

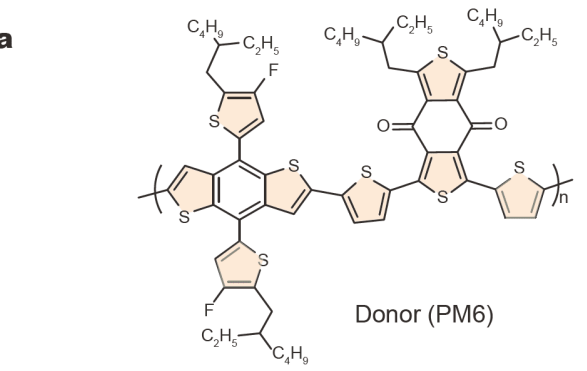

b
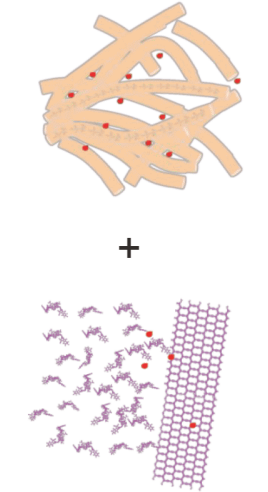

PM6

Y6

$\mathrm{H}_{2} \mathrm{O}$

CF

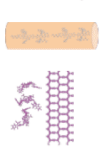

•

2.

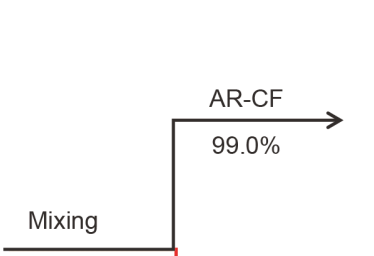

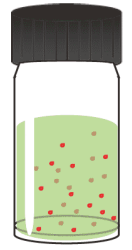

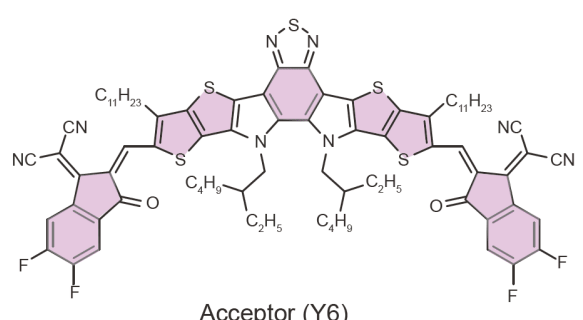

Acceptor (Y6)
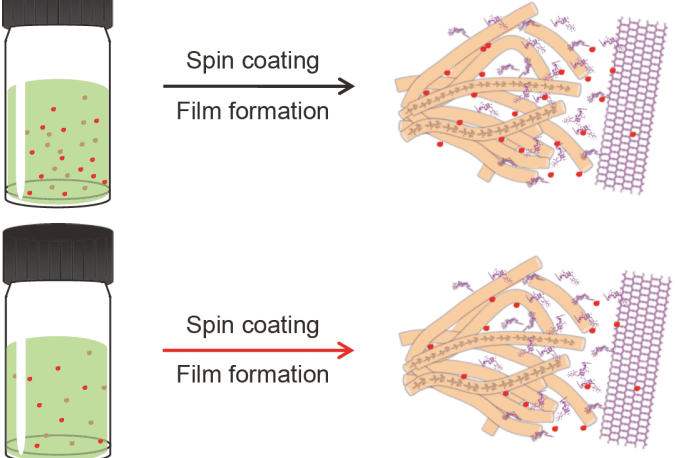

(ii)

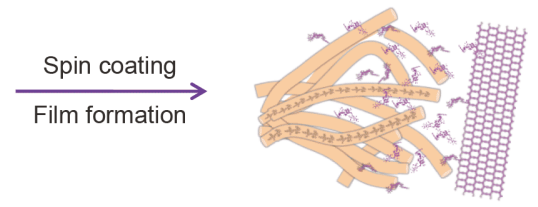

(iii)
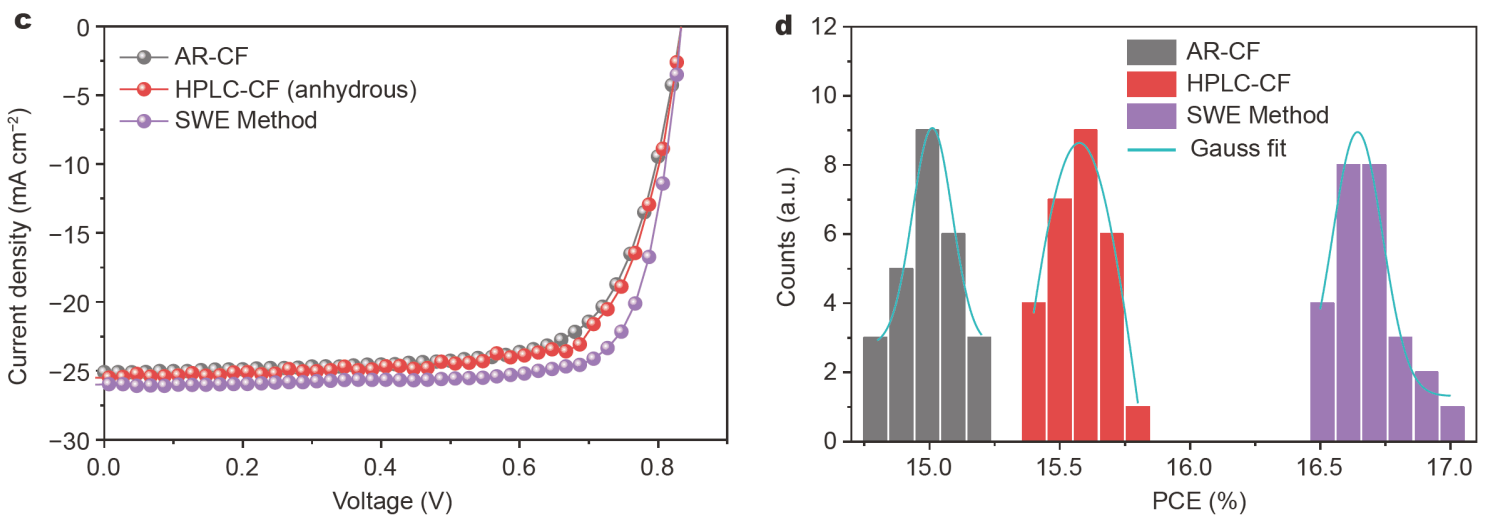

Figure 1 Effect of water removal through various strategies on device performance. (a) Molecular structures of PM6 and Y6. (b) Left: the presence of water-induced traps (red) in the microstructures of polymer (light orange) and small molecule acceptor (lavender) materials. Middle: methods of water removal in BHJ OSCs, including using AR-CF, anhydrous HPLC-CF and SWE method. Right: (i) AR-CF-processed PM6:Y6 blend initially containing residual water after spin-coating. (ii) HPLC-CF-processed PM6:Y6 blend initially containing residual water after spin-coating. The residual water molecules result from the photovoltaic materials that absorbed the water during the preparation and transportation in air. (iii) HPLC-CFprocessed PM6:Y6 blend prepared with the SWE method. A short anneal for $20 \mathrm{~min}$ is used, which removes the solvent and water molecules in the bottle. (c) $J-V$ characteristics of the relevant devices based on the various blends coated according to the above-mentioned solution preparation conditions. (d) Histograms of the PCE counts for 26 individual AR-CF devices, 26 individual HPLC-CF devices, and 26 individual SWE devices.

blend and $28.04 \AA$ for the TA-treated blend, respectively, indicating the higher molecular crystallinity and ag- gregation strength in the annealed blends and thus the changes of the corresponding bulk microstructures. Be- 
Table 1 Summary of photovoltaic parameters of the optimized PM6:Y6 solar cells, measured under the illumination of AM $1.5 \mathrm{G}$ at $100 \mathrm{~mW} \mathrm{~cm}^{-2}$

\begin{tabular}{|c|c|c|c|c|c|}
\hline Processing conditions & $V_{\mathrm{OC}}(\mathrm{V})$ & $J_{\mathrm{SC}}\left(\mathrm{mA} \mathrm{cm}^{-2}\right)$ & $J_{\mathrm{SC}, \mathrm{EQE}}^{\mathrm{a}}\left(\mathrm{mA} \mathrm{cm}{ }^{-2}\right)$ & FF (\%) & $\mathrm{PCE}_{\max }\left(\mathrm{PCE}_{\text {avg }}\right)(\%)$ \\
\hline AR-CF & 0.833 & 25.39 & 24.57 & 72.11 & $15.25\left(14.97^{\mathrm{b}}\right)$ \\
\hline HPLC-CF & 0.833 & 25.41 & 24.74 & 74.79 & $15.83\left(15.59^{\mathrm{b}}\right)$ \\
\hline $\operatorname{SWE}^{\mathrm{c}}$ & 0.833 & 25.99 & 25.21 & 78.98 & $17.10\left(16.73^{b}\right)$ \\
\hline SWE (AR-CF) & 0.832 & 25.59 & 24.81 & 74.14 & $15.79\left(15.46^{\mathrm{d}}\right)$ \\
\hline SWE (HPLC-CF) & 0.836 & 25.77 & 25.04 & 75.84 & $\left(15.81^{\mathrm{d}}\right)$ \\
\hline
\end{tabular}

a) $J_{\mathrm{SC}, \mathrm{EQE}}$ represents the integrated current density obtained from EQE spectra. b) The average PCE values with standard deviations were obtained from twenty devices. c) The anhydrous HPLC-CF purified in our lab was used to conduct the SWE method. d) The average PCE values with standard deviations were obtained from eight devices.

sides, we suspect that some high boiling-point solvents and small molecule additives can also remove water molecules from the coated film. Given however, our current understanding of how solvent and solid additives behave and affect the construction of a $\mathrm{BHJ}$ blend microstructure during the film formation in OSCs $[8,42,43]$, this may also be questionable in the OSCs for the removal of water molecules or clusters [27].

Factually, the small amount of water molecules or clusters in the photoactive layer, generally inducing poor charge transport properties of both holes and electrons, not only comes from the processing solvents but also is closely related to the photovoltaic materials themselves. It is because the molecular structures of photovoltaic materials containing strong hydrogen accepting groups have extremely high sensitivity to the interaction with water molecules. In order to effectively remove water molecules or clusters contained in the photovoltaic materials and minimize the morphological changes of optimal BHJ blends, here we successfully developed an SWE strategy for the removal of water-related traps, as depicted in Fig. 1b. Of note is that the purchased HPLC-CF is further dried and dehydrated to obtain the anhydrous CF solvent (namely, anhydrous HPLC-CF in this work). Instead of using the HPLC-CF prepared solution to directly form the active layer, in the SWE strategy we first remove the anhydrous HPLC-CF and water molecules by heating the glass bottle and then add anhydrous HPLC-CF again to achieve the same concentration for fabrication of $\mathrm{BHJ}$ thin films. Of particular note is that the boiling point $\left(56.3^{\circ} \mathrm{C}\right.$ ) of the azeotrope (e.g., $97 \% \mathrm{CF}$ and $3 \%$ water) can be lower than that of any of the constituents $\left(61^{\circ} \mathrm{C}\right.$ for $\mathrm{CF}$ and $100^{\circ} \mathrm{C}$ for water, respectively), referred to as a positive azeotrope [27]. Thus, this SWE treatment can remove water more efficiency than that of drying active layer materials in the oven. In addition, because of the more polar nature of the orthogonal solvents allowing CF molecules to interact with water molecules more strongly, the SWE method will make it easier to remove water molecules entirely resulting in the overall better photovoltaic performance observed. As shown in Fig. 1c and Table 1, the SWE devices showed a high PCE of 17.10\% $\left(V_{\mathrm{oc}}=0.833 \mathrm{~V}, J_{\mathrm{sc}}=25.99 \mathrm{~mA} \mathrm{~cm}{ }^{-2}, \mathrm{FF}=78.98 \%\right)$, which is the best performance reported for the pure binary PM6: Y6 devices to date $[5,6,41]$. Relevant statistical photovoltaic metrics are also provided in Fig. 1d, which manifest great reproducibility of the high PCE output using the SWE method. Besides, in order to investigate the molecular pre-aggregation and analyze the effect of stirring time of the final solutions on device performance, we extended the stirring time from $15 \mathrm{~min}$ to $15 \mathrm{~h}$ for device fabrication. The $J-V$ curves of the devices based on various solution stirring time periods are shown in Fig. S6, and the corresponding photovoltaic parameters are summarized in Table S6. Both devices based on different stirring time periods showed the comparable device efficiencies, indicating that molecular pre-aggregation may not exist in the final solution when fresh anhydrous HPLC-CF solvent is added. So molecular pre-aggregation is not a factor that improves the corresponding performance investigated in this work.

To further investigate the effects of trace water on device performance, we added the purchased $\mathrm{AR}-\mathrm{CF}$ and HPLC-CF solvents into the dried bottles containing anhydrous active layer materials, respectively, and then fabricated the relevant devices under the same conditions. As shown in Fig. S7 and Table S1, the efficiencies of the SWE-treated devices processed by the AR-CF and HPLC$\mathrm{CF}$ solvents are higher than those of the untreated devices, but still lower than that of the SWE-treated devices processed by the anhydrous HPLC-CF solvent purified in our lab. The results indicate that removing water molecules in the photovoltaic materials and relevant solvents can effectively improve the device performance. The EQE spectra of the relevant devices are exhibited in Fig. S8, and display a similar photo-response in the region from 
300 to $950 \mathrm{~nm}$. Table 1 also provides the integrated $J_{\mathrm{sc}}$ values associated with the EQE data, which well match the tested $J_{\mathrm{sc}}$ values. Apart from the $J_{\mathrm{sc}}$, the FF values in the relevant devices also show an obvious difference (72.11\% for AR-CF device, $74.79 \%$ for HPLC-CF device, $78.98 \%$ for SWE device, $74.14 \%$ for AR-CF-based SWE device and $75.84 \%$ for HPLC-CF-based SWE device).

The above photovoltaic parameters of the corresponding devices drive us to further explore the light-soaking stability of the devices held under a protective atmosphere. The lamp provides an illumination intensity of $100 \mathrm{~mW} \mathrm{~cm}^{-2}$ and has a close spectral match to the AM $1.5 \mathrm{G}$ spectrum over the visible wavelengths (Fig. S9). Fig. S10 shows the degradation trends of the normalized photovoltaic performance of the corresponding devices based on different processing conditions. The average PCEs of the PM6:Y6 devices maintained approximately 79\% (AR-CF), 80\% (HPLC-CF), and 83\% (SWE) of the corresponding initial performances, respectively, after approximately $400 \mathrm{~h}$ light-soaking under one sun. Among these, the SWE-based devices possess slightly better photo-stability, strongly indicating the benefit of this SWE strategy. Notably, the difference in light-soaking stabilities of these three types of devices can be partially due to the synergistic effects of the slight morphology evolution and interface attenuation, while quantitative evaluation of their photo-stability performance is beyond the scope of the present work. Despite, the recent results indicate that our water trap passivation strategy not only provides significant enhancements in device performance but may also offer a practical route to improving longterm stability of OSCs.

\section{Removing water-induced traps to improve $\boldsymbol{J}_{\mathrm{sc}}$ and FF}

To systematically investigate the specific effects of waterrelated traps on device performance, we firstly fabricated hole-only and electron-only devices with the structures of ITO/PEDOT:PSS/active layer/ $\mathrm{MoO}_{3} / \mathrm{Ag}$ and ITO/ZnO/ active layer/PDINO/Al, respectively. The hole-only and electron-only mobilities of the relevant blends were investigated by analyzing the $J-V$ characteristics of singlecarrier devices (Fig. 2a for hole-only devices and Fig. 2b for electron-only devices), and their results are summarized in Table 2. Applying the model method as in Ref. [23], the fitting to the experimental results shows that the hole mobilities of the blends are $1.346 \times 10^{-4} \mathrm{~cm}^{2} \mathrm{~V}^{-1} \mathrm{~s}^{-1}$ for AR-CF, $1.380 \times 10^{-4} \mathrm{~cm}^{2} \mathrm{~V}^{-1} \mathrm{~s}^{-1}$ for HPLC-CF, and $1.468 \times 10^{-4} \mathrm{~cm}^{2} \mathrm{~V}^{-1} \mathrm{~s}^{-1}$ for SWE method, respectively. In addition, the electron mobilities of the corresponding blends are $1.222 \times 10^{-4} \mathrm{~cm}^{2} \mathrm{~V}^{-1} \mathrm{~s}^{-1}$ for AR-CF, $1.335 \times$
$10^{-4} \mathrm{~cm}^{2} \mathrm{~V}^{-1} \mathrm{~s}^{-1}$ for HPLC-CF, and $1.503 \times$ $10^{-4} \mathrm{~cm}^{2} \mathrm{~V}^{-1} \mathrm{~s}$ for SWE method, respectively. Notably, the SWE-processed blends show higher and slightly more balanced hole and electron mobilities compared with the AR-CF- and HPLC-CF-processed blends. The results suggest that charge carriers can be transmitted more efficiently, leading to high FF values as aforementioned in Table 1. Apart from the SCLC data, we also employed photo-CELIV to determine the ambipolar CE from an actual photovoltaic device. As shown in Fig. S11, photoCELIV curves have been measured using different experimental conditions, differing in delay time. In addition, Fig. $2 c$ exhibits the photocurrent transient recorded by applying a $2 \mathrm{~V} / 60 \mu$ s linearly increasing reverse bias pulse to the relevant devices after a $0.5 \mu$ s delay time. The average mobilities in devices are provided in Table S7, calculated from Figs S11 and S12. The average mobility of SWE devices $\left(4.02 \times 10^{-4} \mathrm{~cm}^{2} \mathrm{~V}^{-1} \mathrm{~s}^{-1}\right)$ is still higher than those of AR-CF $\left(1.12 \times 10^{-4} \mathrm{~cm}^{2} \mathrm{~V}^{-1} \mathrm{~s}^{-1}\right)$ and HPLC-CF $\left(2.00 \times 10^{-4} \mathrm{~cm}^{2} \mathrm{~V}^{-1} \mathrm{~s}^{-1}\right)$ devices. The results confirm the mobility trends observed by SCLC measurements.

To experimentally determine whether, indeed, minute trace of water is somehow involved in the observed trap formation, we further repeated the $J$ - $V$ curves of relevant devices (Fig. 2a, b), which shows the logarithmic slopes, slope $=\mathrm{d}(\log j) / \mathrm{d}(\log V) \quad[21,30,44]$. The double-log representation exhibits weak humps in the $J-V$ curves of the corresponding devices around $1 \mathrm{~V}$, highlighting the trapfilling regime [21]. Importantly, we find that the use of anhydrous HPLC-CF instead of AR-CF to prepare photoactive layers can slightly suppress the pronounced peaks at low bias, which reveals the presence of energetic traps (e.g., water-induced traps) $[21,22,45]$. This also illustrates that other sources of water-induced traps in the anhydrous CF-processed blends are likely to be present. Notably, the humps in the $J$ - $V$ curves of SWE-treated holeonly and electron-only devices are not obvious at low bias, indicating that this approach can more effectively remove the water-induced traps, carried by the material itself in the active layer. Following the previous studies $[22,44,46]$, the peaks can map out the effective trap depth $\left(E_{\mathrm{t}}\right)$, the total concentration of electron traps $\left(N_{\mathrm{t}}\right)$, and the Gaussian trap density of states (DOS) $\left(\sigma_{\mathrm{DOS}}\right)$ values in the photoactive layers. Thus, we derived these corresponding parameters by directly fitting the $J-V$ curves [23], as summarized in Table 2. Of note is that $N_{\mathrm{t}}$ and, to a lesser degree, $E_{\mathrm{t}}$ depend on the amount of water molecules as discussed in more detail in Ref. [21]. Obviously, the SWE method can effectively suppress water-induced traps, reduce the $N_{\mathrm{t}}$ and $E_{\mathrm{t}}$ values and thus lead to a significant 

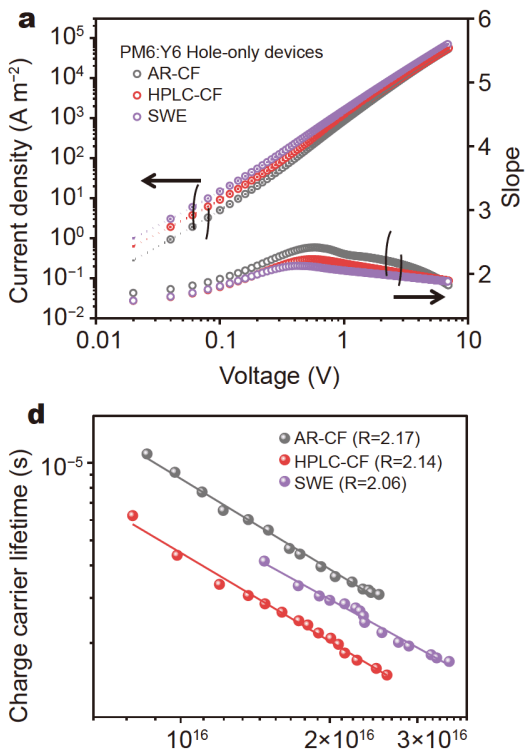

Charge carrier density $\left(\mathrm{cm}^{-3}\right)$

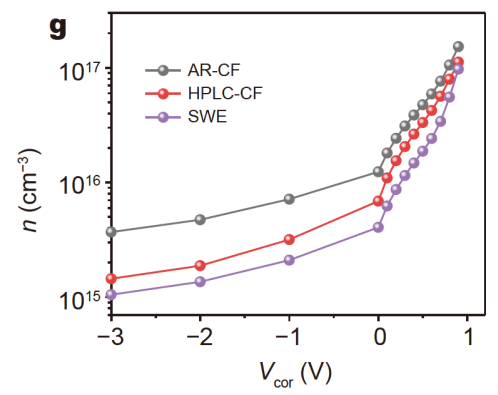

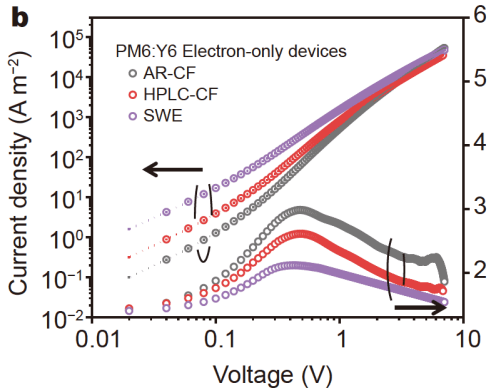
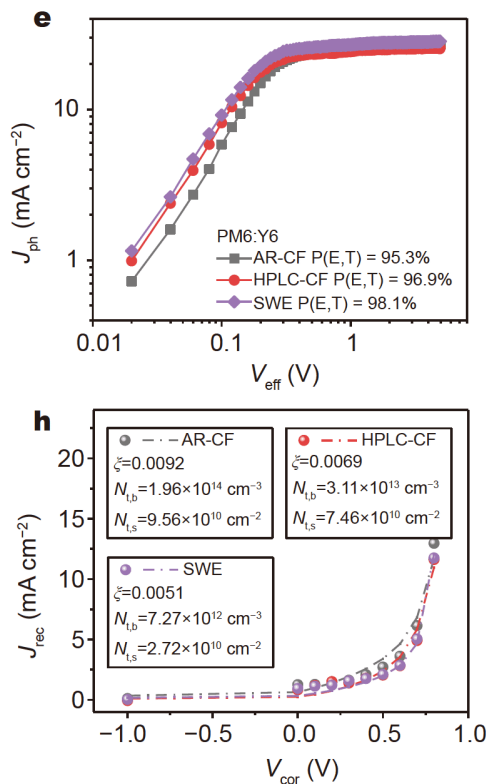
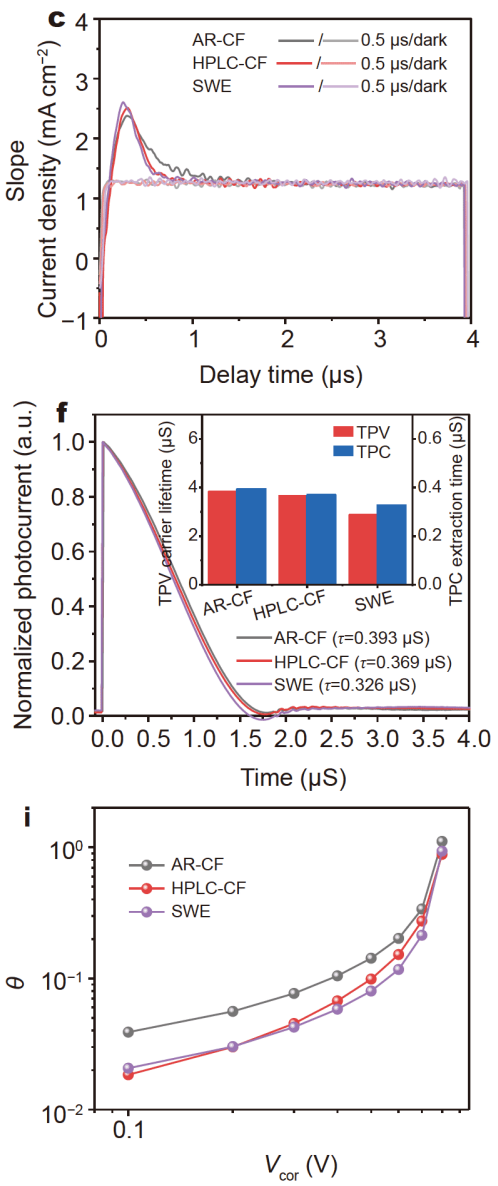

Figure 2 Charge transport, extraction and recombination in blends. The corresponding current-voltage (I-V) curves from (a) hole-only devices (symbols) or (b) electron-only devices (symbols) and model fits (dashed lines) for the PM6:Y6 blends with different processing conditions. Slope versus relevant voltage curves for the PM6:Y6 blends with different processing conditions. (c) The photo-CELIV traces for the devices after a delay time of $0.5 \mu$ s. (d) Charge carrier lifetime $\tau$, obtained from TPV measurements, as a function of charge density $n$, calculated from CE curves under $V_{\mathrm{oc}}$ conditions (from 0.15 to 2.50 suns). The dashed lines represent linear fits of the data. (e) Photocurrent versus $V_{\text {eff }}$ in the relevant devices based on different processing conditions. (f) Normalized TPC data for the relevant devices. The illumination pulse intensity was $150 \mathrm{~mW} \mathrm{~cm}$ (light pulse of $50 \mu \mathrm{s}$ ). Inset: the figure of the comparison of charge carrier lifetime $\tau$ (obtained from TPV tests) and charge extraction time $\tau$ (obtained from TPC tests). The bulk-heterojunction systems of AR-CF, HPLC-CF and SWE of (g) charge carrier density $n$, determined via capacitance spectroscopy, (h) recombination current density $J_{\text {rec }}$ and fitting curves, and (i) competitive factors $\theta$, determined via effect extraction time $\tau_{\text {ex }}$ and charge carrier lifetime $\tau_{\text {rec. }}$

Table 2 Summary of the relevant physical parameters of the analysis of current-voltage characteristics, as well as the data of transient spectroscopic measurements

\begin{tabular}{|c|c|c|c|c|c|c|c|c|c|c|c|c|}
\hline \multirow{2}{*}{$\begin{array}{l}\text { Processing } \\
\text { conditions }\end{array}$} & \multicolumn{4}{|c|}{ Hole-only devices } & \multicolumn{4}{|c|}{ Electron-only devices } & \multirow[b]{2}{*}{$\mu_{\mathrm{h}} / \mu_{\mathrm{e}}$} & \multicolumn{3}{|c|}{ Solar cells } \\
\hline & $\begin{array}{c}\text { Mobility }\left(\times 10^{-4}\right. \\
\left.\mathrm{cm}^{2} \mathrm{~V}^{-1} \mathrm{~s}^{-1}\right)\end{array}$ & $\underset{\left(\times 10^{23} \mathrm{~m}^{-3}\right)}{N_{\mathrm{t}}}$ & $\begin{array}{c}E_{\mathrm{t}} \\
(\mathrm{eV})\end{array}$ & $\begin{array}{l}\sigma_{\mathrm{DOS}} \\
(\mathrm{eV})\end{array}$ & $\begin{array}{c}\text { Mobility }\left(\times 10^{-4}\right. \\
\left.\mathrm{cm}^{2} \mathrm{~V}^{-1} \mathrm{~s}^{-1}\right)\end{array}$ & $\left(\times 10^{23} \mathrm{~m}^{-3}\right)$ & $\begin{array}{c}E_{\mathrm{t}} \\
(\mathrm{eV})\end{array}$ & $\begin{array}{l}\sigma_{\mathrm{DOS}} \\
(\mathrm{eV})\end{array}$ & & $R$ & $\begin{array}{c}\tau_{1}^{\mathrm{a}} \\
(\mu \mathrm{s})\end{array}$ & $\begin{array}{l}\tau_{2}^{\mathrm{b}} \\
(\mu \mathrm{s})\end{array}$ \\
\hline CF (AR) & 1.346 & 2.359 & 0.375 & 0.140 & 1.222 & 2.553 & 0.377 & 0.141 & 1.10 & 2.17 & 3.83 & 0.393 \\
\hline CF (HPLC) & 1.380 & 2.311 & 0.374 & 0.140 & 1.335 & 2.373 & 0.375 & 0.140 & 1.03 & 2.14 & 3.65 & 0.369 \\
\hline SWE & 1.468 & 2.196 & 0.373 & 0.140 & 1.503 & 2.150 & 0.372 & 0.140 & 0.98 & 2.06 & 2.86 & 0.326 \\
\hline
\end{tabular}

a) Charge carrier lifetime $\tau_{1}$ achieved from the TPV spectra measured under one sun. b) CE time $\tau_{2}$ obtained from TPC tests. 
improvement in device performance (Fig. 1c and Table 1). Besides, inspired by the findings in Ref. [21], we also tried SVA and TA post-treatments to remove the water-filled nanoscopic voids in the disordered morphology of the active layer. Unfortunately, these methods may not significantly reduce the (majority of) water-filled nanovoids (Fig. S13 and Table S8), but will change the D/ A microstructures of $\mathrm{BHJ}$ blends, resulting in the poor photovoltaic performance (Fig. S14 and Table S9) $[19,36,47]$. It should be noted that the minor effects of SVA and TA on removing the water-related traps, which is beyond the scope of this work, suggests that either incomplete removal and/or reuptake of water limits the effectiveness of this processing step. In stark contrast, the effect of SWE pre-treatment method is much stronger, leading to almost complete removal of the trapping peaks (holes and electrons) and a significant increase in current density.

To further understand the effects of SWE method on the water-related traps in $\mathrm{BHJ}$ blends, we studied the carrier recombination dynamics and the collection processes in the three devices by employing transient spectroscopic techniques. Here we combined TPV (Fig. S15) and CE (Fig. S16) techniques to achieve the charge carrier lifetime $\tau$ as a function of charge carrier density $n$ under open-circuit conditions, $\tau(n)$. Further employing the equation:

$\tau=\tau_{0}\left(n_{0} / n\right)^{\lambda}$

where $\lambda$ is the so-called recombination exponent, and $n_{0}$ and $\tau_{0}$ are constants [5,35], a non-geminate recombination order $R(R=\lambda+1)$ can be calculated as shown in Fig. $2 \mathrm{~d}$ and Table 2. A lower recombination order value $(R=2.06)$ for the SWE device with a shorter charge carrier lifetime $\tau_{1}\left(\tau_{1}=2.86 \mu \mathrm{s}\right)$ measured under one sun, as compared with the AR-CF device $\left(R=2.17\right.$ and $\tau_{1}=$ $3.83 \mu \mathrm{s})$ and HPLC-CF device $\left(R=2.14\right.$ and $\left.\tau_{1}=3.65 \mu \mathrm{s}\right)$, can be found, suggesting that the SWE method can effectively reduce the carrier recombination loss in blend morphology and thus yield overall improved $J_{\text {sc }}$ and FF values (Table 1). In addition, the correlation between $V_{\text {oc }}$ or $J_{\mathrm{sc}}$ and light intensity $\left(P_{\text {light }}\right)$ were studied [48], as provided in Fig. S17, respectively. The relationships between the $J_{\text {sc }}$ or $V_{\text {oc }}$ and $P_{\text {light }}$ as well as the detailed formula descriptions are deliberately the same as used in Ref. [9]. The results as provided in Supplementary Note 1 indicate the more balanced charge transport and less trap-assisted recombination in the SWE devices when compared with AR-CF and HPLC-CF devices, thus leading to improvements in $J_{\mathrm{sc}}$ and FF.
Here we further calculated the exciton dissociation probabilities $\left(P(E, T)\right.$ as exhibited in Fig. 2e, $P(E, T)=J_{\mathrm{ph}} /$ $J_{\text {sat }}$, where $J_{\text {sat }}$ is the saturation current density) [35], which can be used to assess the exciton dissociation and charge collection efficiency in the corresponding devices. The $P(E, T)$ for the three types of devices were $95.3 \%$ (AR-CF device), 96.9\% (HPLC-CF device) and 98.1\% (SWE device), respectively. Among these three devices, the SWE device shows the highest $J_{\mathrm{ph}} / J_{\text {sat }}$ value of $98.1 \%$ under short-circuit and maximum output power condition, indicating the more efficient processes of exciton dissociation and charge collection in the photoactive layer. We also conducted the TPC technique to investigate the dwell time of charges in the active layer prior to $\mathrm{CE}$ at the electrodes. As provided in Fig. $2 \mathrm{f}$, the extraction time of the relevant devices was extracted to be $\tau_{2}$ $=0.393 \mu \mathrm{s}$ for the AR-CF device, $\tau_{2}=0.369 \mu \mathrm{s}$ for the HPLC-CF device, $\tau_{2}=0.326 \mu$ s for SWE devices, respectively. The shorter carrier lifetime in the SWE device can be ascribed to less charge recombination and fewer waterinduced traps within the blend supported by the characterizations of the above-discussed transient spectroscopic techniques (Fig. 2c, d) and the analysis of SCLC measurements (Fig. 2a, b). Note that the trend of extraction lifetime is almost consistent with the trend of carrier lifetime measured by TPV measurements (an inset figure in Fig. 2f).

To quantitatively confirm the effects of water-related traps on device performance, the capacitance spectroscopy was used to calculate the carrier density $n$ and other extension parameters such as the effective mobility $\mu_{\text {eff }}$ or recombination coefficients $k_{\text {rec }}$ [49-52]. Detailed descriptions are provided in the Supplementary Note 2. The chemical capacitance $C_{\text {chem }}$ derived from the capacitance difference between dark and illumination (Fig. S18) and the charge carrier density $n$ derived from the $C_{\text {chem }}$ integral, are shown in Fig. S19 and Fig. 2g [53]. All measured carrier density $n$ values are in the range of $10^{15}-10^{17} \mathrm{~cm}^{-3}$, while under the same reverse bias, AR-CF equipped the maximum carrier density, followed by HPLC-CF, while the carrier density of SWE system was relatively small. Apart from the carrier density $n$ obtained, the effective mobility $\mu_{\text {eff }}$ associated with $n$ is also known, as provided in Table S10 [54]. As shown in Fig. S20, the variation trend of average mean values of effect mobility $\mu_{\text {eff }}$ of three systems associated with carrier density $n\left(5.80 \times 10^{-5} \mathrm{~cm}^{2} \mathrm{~V}^{-1} \mathrm{~s}^{-1}\right.$ for AR-CF devices, 1.03 $\times 10^{-4} \mathrm{~cm}^{2} \mathrm{~V}^{-1} \mathrm{~s}^{-1}$ for HPLC-CF devices, $1.69 \times$ $10^{-4} \mathrm{~cm}^{2} \mathrm{~V}^{-1} \mathrm{~s}^{-1}$ for SWE-anhydrous CF devices, respectively) can be well matched with the electron and hole 
mobility obtained from SCLC measurements (see Table 2).

In order to further quantitatively analyze of the FF difference caused by water-induced recombination, the recombination current density $\left(J_{\text {rec }}\right)$ superposed by three recombination mechanism currents (bimolecular recombination $\left(J_{\text {rec,bm }}\right)$, bulk trap assisted recombination $\left(J_{\text {rec,bulk }}\right)$ and surface trap-assisted recombination $\left(J_{\text {rec,surf }}\right)$ ) was fitted to obtain the recombination coefficient $\left(k_{\mathrm{bm}}\right)$, $k_{\mathrm{t}, \mathrm{b}}$, Langevin coefficient $(\xi)$, bulk and surface trap density $\left(N_{\mathrm{t}, \mathrm{b}}, N_{\mathrm{t}, \mathrm{s}}\right)$ (Fig. 2h) [52]. The bimolecular recombination coefficient $k_{\mathrm{bm}}$ for three systems has a relatively small difference (AR-CF: $k_{\mathrm{bm}}=3.31 \times 10^{-13} \mathrm{~cm}^{3} \mathrm{~s}^{-1}$, HPLC-CF: $k_{\mathrm{bm}}=8.06 \times 10^{-13} \mathrm{~cm}^{3} \mathrm{~s}^{-1}$, SWE: $k_{\mathrm{bm}}=8.80 \times$ $10^{-13} \mathrm{~cm}^{3} \mathrm{~s}^{-1}$ ), which suggested that performance differences between devices would be due to the contribution of trap-assisted recombination. These similar values of surface trap density $N_{\mathrm{t}, \mathrm{s}}$ for AR-CF, HPLC-CF and SWE systems indicate that surface trap-assisted recombination has less effect on the performance $\left(9.56 \times 10^{-10}, 7.46 \times\right.$ $10^{-10}$ and $2.72 \times 10^{-10} \mathrm{~cm}^{-2}$, respectively). Moreover, the value of $N_{\mathrm{t}, \mathrm{b}}$ with magnitude difference $\left(1.96 \times 10^{-14} \mathrm{~cm}^{-3}\right.$ for AR-CF, $3.11 \times 10^{-13} \mathrm{~cm}^{-3}$ for HPLC-CF and $7.27 \times 10^{-12} \mathrm{~cm}^{-3}$ for SWE) and the value of $k_{\mathrm{t}, \mathrm{b}}$ with a large multiple difference $(6600.73,3570.07$ and $1133.41 \mathrm{~s}^{-1}$, respectively) indicate that the recombination caused by bulk trap-assisted is an important factor affecting the performance difference. Furthermore, the charge carrier lifetime $\left(\tau_{\text {rec }}\right)$ can be calculated by the recombination coefficients $k_{\mathrm{bm}}, k_{\mathrm{t}, \mathrm{b}}$ and $k_{\mathrm{t}, \mathrm{s}}\left(V_{\mathrm{cor}}\right)$, and the effect extraction time $\left(\tau_{\mathrm{ex}}\right)$ can also be quantized with carrier density $n$ obtained from $J-V$ curves [54]. By calculating the ratio of the $\tau_{\text {ex }}$ to the $\tau_{\text {rec }}$, the voltage-related competitive factors $\theta$ can be obtained $\left(\theta=\tau_{\text {rec }} / \tau_{\text {ex }}\right)$, which are generally considered to be related to the $\mathrm{FF}$ and $J_{\mathrm{SC}}$ of the devices [49,55-57]. As shown in Fig. 2i, compared with the blends treated with AR-CF, HPLC-CF and SWEprocessed blends had lower competitive factor $\theta-V_{\text {cor }}$ curves, which illustrate more extraction and less recombination. Overall, the SCLC analysis coupled with the carrier recombination dynamics and CE properties as well as the capacitance spectroscopy measurements finally underpin the influence of water-induced traps on device performance as outlined above and provide detailed insight into special effects of water-induced traps being responsible for photovoltaic parameters.

\section{Universality of SWE method applied into OSCs}

As discussed above, the SWE approach can efficiently reduce water-related traps, suppress carrier recombina- tion loss and thus improve photovoltaic performance of the binary PM6:Y6 system. If the method proposed above is conceptually correct, it should work well in other photovoltaic systems. Thus, four other photovoltaic systems, including J101:ITIC [58], J71:MeIC [34], PTB7-Th: $\mathrm{PC}_{70} \mathrm{BM}$ [59] and TBFT-TR:PC ${ }_{70} \mathrm{BM}$ [60] (Fig. 3a), were introduced to further explore its versatility and effectiveness in OSCs. The $J-V$ curves of the corresponding best-performing devices are depicted in Fig. 3b. The details of device fabrication are described in the EXPERIMENTAL SECTION and the detailed photovoltaic parameters are summarized in Table S11. Unsurprisingly, on the basis of their photovoltaic parameters, it is quite clear that the same trend as we observed in PM6:Y6 system was obtained. After SWE processing treatments, the PCE of J101:ITIC system improves from $12.39 \%$ to $13.19 \%$; the PCE of J71:MeIC system improves from $12.20 \%$ to $13.09 \%$; the PCE of PTB7-Th: $\mathrm{PC}_{70} \mathrm{BM}$ system improves from $8.86 \%$ to $10.04 \%$; the PCE of TBFT-TR: $\mathrm{PC}_{70} \mathrm{BM}$ system improves from $8.70 \%$ to $9.25 \%$, surpassing $6.5 \%, 7.3 \%, 13.3 \%$ and $6.3 \%$ their original average values, respectively (Fig. 3c, top figure). The higher PCEs of SWE devices compared with HPLC-CF devices are mainly attributed to the improvement of $J_{\mathrm{sc}}$ and $\mathrm{FF}$ (Table S11).

Furthermore, we also conducted the hole-only and electron-only mobilities of the four photovoltaic systems fabricated with and without SWE treatments to analyze the $J-V$ characteristics of single-carrier devices (Fig. S21 for hole-only devices and Fig. S22 for electron-only devices). The calculated results, including charge carrier mobilities, $N_{\mathrm{t}}, E_{\mathrm{t}}$ and $\sigma_{\mathrm{DOS}}$ values, are summarized in Tables S12 and S13, respectively. As exhibited in Fig. 3c (bottom figure), the SWE strategy effectively reduced the trap density of these fullerene and non-fullerene-based hole-only devices. After the SWE treatments, the $N_{\mathrm{t}}$ of the SWE-based J101:ITIC system decreases from $2.763 \times 10^{23}$ to $2.201 \times 10^{23} \mathrm{~m}^{-3}$; the $N_{\mathrm{t}}$ of the SWE-based J71:MeIC system decreases from $2.828 \times 10^{23}$ to $2.249 \times 10^{23} \mathrm{~m}^{-3}$; the $N_{\mathrm{t}}$ of the SWE-based PTB7-Th:PC ${ }_{70} \mathrm{BM}$ system decreases from $2.810 \times 10^{23}$ to $2.167 \times 10^{23} \mathrm{~m}^{-3}$; the $N_{\mathrm{t}}$ of the SWE-based TBFT-TR:PC ${ }_{70} \mathrm{BM}$ system decreases from $2.851 \times 10^{23}$ to $2.543 \times 10^{23} \mathrm{~m}^{-3}$, respectively. In addition, the SWE method also reduces the total concentration of electron traps in the relevant electron-only devices. The $N_{\mathrm{t}}$ of the SWE-based J101:ITIC system decreases from $2.787 \times 10^{23}$ to $2.231 \times 10^{23} \mathrm{~m}^{-3}$; the $N_{\mathrm{t}}$ of the SWE-based J71:MeIC system decreases from $2.916 \times 10^{23}$ to $2.390 \times 10^{23} \mathrm{~m}^{-3}$; the $N_{\mathrm{t}}$ of the SWE-based PTB7-Th: $\mathrm{PC}_{70} \mathrm{BM}$ system decreases from $2.716 \times 10^{23}$ to 

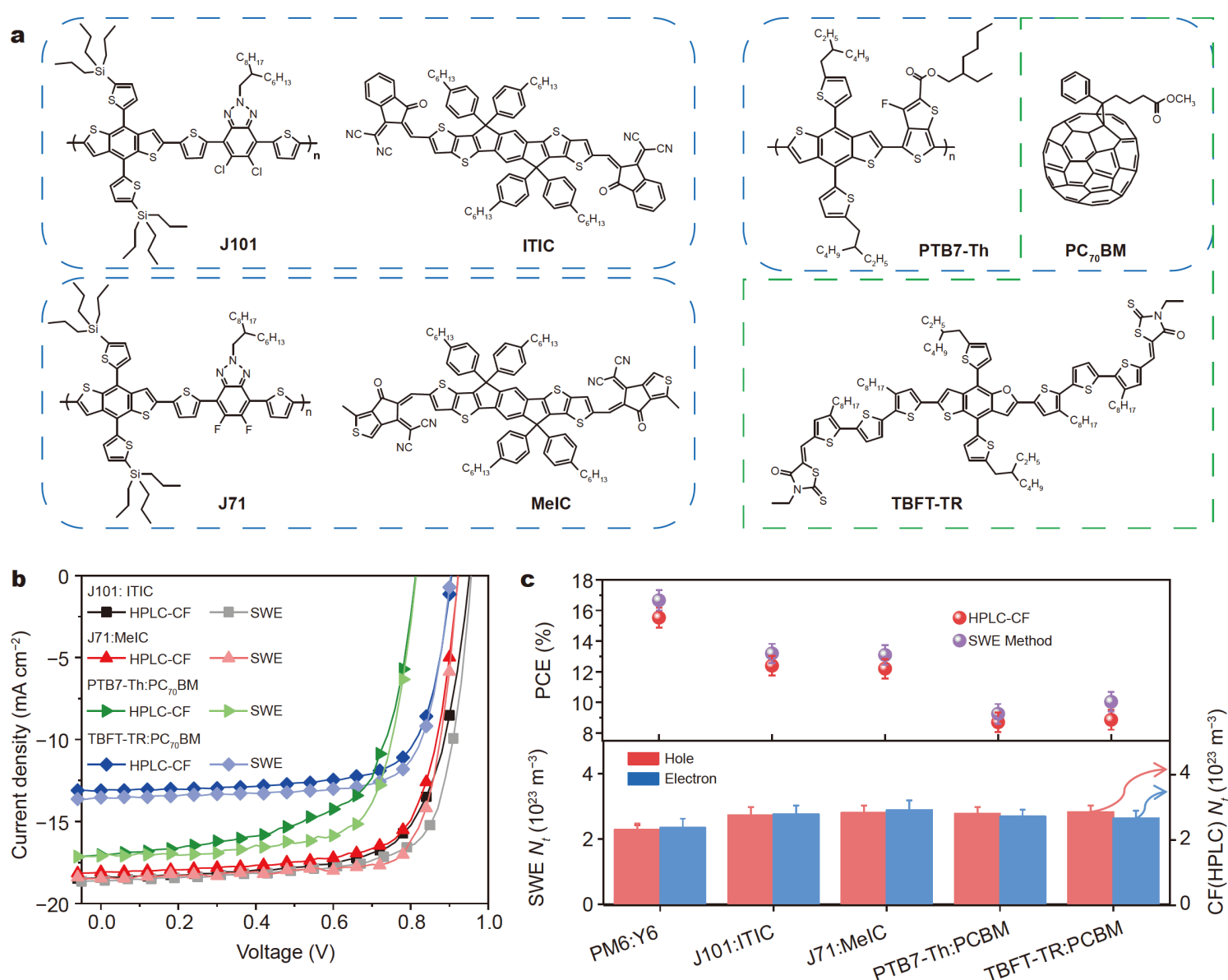

Figure 3 Chemical structures, device performance and transport properties. (a) Molecular structures of the four photovoltaic systems, including J101:ITIC, J71:MeIC, PTB7-Th:PC70BM, and TBFT-TR:PC70BM. (b) J-V characteristics of the four types of devices with and without SWE approaches. (c) Top: average PCEs of the five photovoltaic systems without and with SWE treatments; bottom: the electron traps of hole-only devices and electron-only devices for the relevant blends without and with SWE treatments.

$2.309 \times 10^{23} \mathrm{~m}^{-3}$; the $N_{\mathrm{t}}$ of the SWE-based TBFT-TR: $\mathrm{PC}_{70} \mathrm{BM}$ system decreases from $2.661 \times 10^{23}$ to $2.325 \times 10^{23} \mathrm{~m}^{-3}$, respectively. Besides, in all these five photovoltaic systems, it can be easily found that $E_{\mathrm{t}}$ and $\sigma_{\mathrm{DOS}}$ parameters were reduced by employing the SWE strategy in the relevant film formation, and thus PCEs increased obviously, as summarized in Table 1 and Fig. S11. These results not only further demonstrate the SWE approach to be very efficient to remove the water molecules or clusters in photoactive layers, but also strongly highlight its good generality, indicating that the SWE approach is a superior alternative to the common processing technique in fabricating highly-efficient and stable OSCs.

\section{Characterization of SWE-based OLEDs and OFETs}

To further verify the effect of SWE methods on perfor- mance of organic electronics, we fabricated OLEDs (Fig. 4a) and OFETs (Fig. 4c) from the reported polymer SY-PPY and PDPP2TBT (Fig. 4b) with the film spun from various solutions. The details of device fabrication procedures of OLEDs and OFETs are described in the EXPERIMENTAL SECTION. Fig. 4d exhibits the current density-voltage-luminance $(J-V-L)$ characteristics of SYPPY OLEDs without and with SWE treatment. Table S14 summarizes the device performance of these two OLEDs. It can be found that the level of leakage current in HPLC$\mathrm{CF}$ device is higher than that of the SWE device. The HPLC-CF device also shows lower luminance $\left(788 \mathrm{~cd} \mathrm{~m}^{-2}\right)$ than the SWE device $\left(1037 \mathrm{~cd} \mathrm{~m}^{-2}\right)$ at $5.5 \mathrm{~V}$. In addition, Fig. 4e exhibits the luminous and power efficiencies as a function of the applied bias of the relevant SY-PPV OLEDs. The device efficiency is obtained with the SWE method; $1.4 \mathrm{~cd} \mathrm{~A}^{-1}$ at $5.5 \mathrm{~V}$ and $0.85 \mathrm{~lm} \mathrm{~W}^{-1}$ at 
a

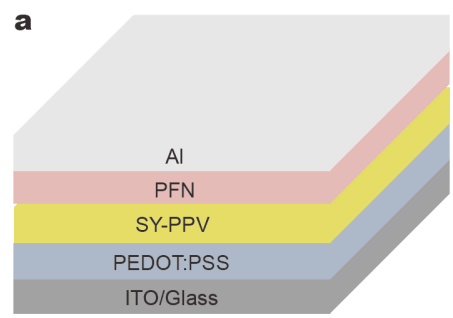

b

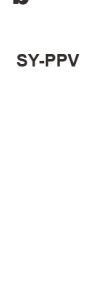

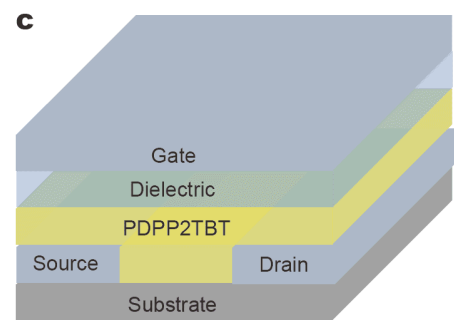
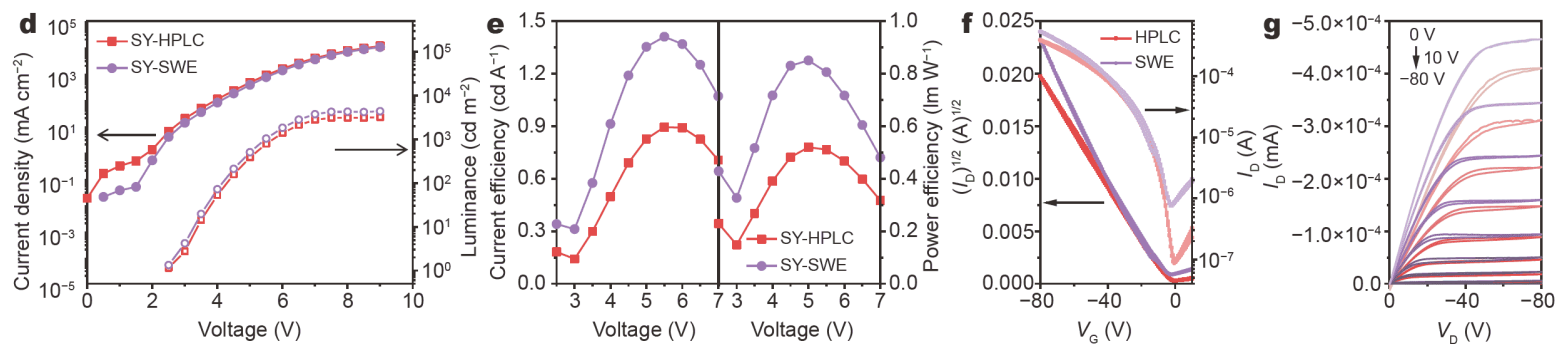

Figure 4 Improving the performance of OLEDs and OFETs with SWE approaches. (a) Device structure of an SY-PPY OLED, (b) chemical structures of SY-PPY and PDPP2TBT. (c) Device structure of a PDPP2TBT OFET. (d) $J$ - $V$ - $L$ characteristics of SY-PPV OLEDs without and with SWE treatments. (e) Luminous ( $\mathrm{cd} \mathrm{A}^{-1}$ ) and power $\left(1 \mathrm{~m} \mathrm{~W}^{-1}\right)$ efficiencies as a function of the applied voltage of the SY-PPV OLEDs. ( $\mathrm{f}$ ) Representative transfer and $(\mathrm{g})$ output characteristics, respectively. The transfer curve was collected with a voltage sweep rate of $50 \mathrm{mV} \mathrm{s}^{-1}$.

$5.0 \mathrm{~V}$. The HPLC-CF device in contrast shows the lower efficiencies of $0.9 \mathrm{~cd} \mathrm{~A}^{-1}$ at $5.5 \mathrm{~V}$ and $0.52 \mathrm{~lm} \mathrm{~W}^{-1}$ at $5.0 \mathrm{~V}$, indicating that the water-related traps as intermolecular voids in films are known to cause non-radiative Shockley-Read-Hall recombination, decreasing the quantum efficiency. The results highlight the fact that this SWE method can effectively remove the water-related traps and offer better electron injection for polymerbased OLEDs.

Apart from the investigated OLEDs, we also fabricated the PDPP2TBT-based OFETs for investigating the practicability of SWE approach. These two types of devices were prepared using the same processing conditions. Fig. $4 \mathrm{f}$, g show the transfer and output plots of the bottom-contact/top-gate OFET devices under nitrogen atmosphere at room temperature. The average field effect mobility $\left(\mu_{\text {avg }}\right)$ was calculated using standard metal-oxidesemiconductor FET (MOSFET) equations from the transfer characteristics of eight devices in the saturation region [61]. Table S15 summarized the $\mu$, on/off current ratio $\left(I_{\text {on }} / I_{\text {off }}\right)$, and threshold voltage $\left(V_{\text {th }}\right)$ of the devices without and with SWE treatment. The electrical performances of PDPP2TBT are similar to those obtained previously [62]. The $\mu_{\text {avg }}\left(0.78 \mathrm{~cm}^{2} \mathrm{~V}^{-1} \mathrm{~s}^{-1}\right)$ of the device with SWE treatment is higher than that of the HPLC-CF device $\left(0.48 \mathrm{~cm}^{2} \mathrm{~V}^{-1} \mathrm{~s}^{-1}\right)$, but there are no specific trends in $I_{\text {on }} / I_{\text {off }}$ and $V_{\text {th }}$. The enhanced carrier mobility in SWE devices further confirms the remarkable impact of SWE treatment on the charge transport of semiconducting polymers, resulting from the removal of water-related traps in PDPP2TBT polymers. This is also demonstrated by the SCLC analysis, as shown in Fig. S23 and Table S16. On the one hand, the humps in the $J-V$ curves of holeonly and electron-only devices with SWE treatments are lower than those of the untreated devices at low bias. On the other hand, the treated diodes show the lower density of electron traps, further suggesting the removal of waterinduced traps carried by PDPP2TBT. Accordingly, it can be concluded that for all these organic electronics, the presence in the active material of water-related traps is known factor that obviously deteriorates device performance. Nevertheless, this demonstrates that our water trap passivation technique may offer a practical route to suppress the water-related trap concentrations in organic semiconductor materials and provide significant enhancements in device performance.

\section{CONCLUSIONS}

Water-related defects are energetically favorable in organic conjugated materials and are more likely to form the intermolecular voids in films, resulting in the worse charge-transport properties of both holes and electrons. In this work we developed an SWE strategy for reducing the water-related trap concentration in OSCs. Taking the PM6:Y6 system as an example, we found that this water trap passivation technique not only provides significant 
enhancements in device efficiencies, but may also offer a practical route to slightly improving long-term stability of OSCs. Of note is that a high PCE of $17.10 \%$ was achieved in the SWE-treated OSCs, which is the highest value among the corresponding binary PM6:Y6 devices. Furthermore, the removal of water-related traps to achieve the reduction of carrier recombination losses in photoactive layers and the improvement of CE properties in devices were confirmed by the analysis of SCLC method, the investigations of exciton dissociation probabilities and the applications of transient spectroscopic techniques (including photo-CELIV, CE, TPV, TPC and capacitance spectroscopy measurements), which is in great accordance with the enhancements of $J_{\mathrm{sc}}$ and FF in SWE devices. Additionally, the increased photovoltaic parameters of the other four fullerene- and non-fullerenebased photovoltaic systems, including J101:ITIC, J71: MeIC, PTB7-Th:PC ${ }_{70} \mathrm{BM}$, and TBFT-TR:PC ${ }_{70} \mathrm{BM}$, in combination with the comparative analysis of relevant hole-only and electron-only mobilities strongly showed us to pin down the universality of SWE strategy. Notably, we also found that the SWE method can improve the device performance of the SY-PPY-based OLEDs and the PDPP2TBT-based OFETs. Overall, simultaneously reducing the water-related trap concentration and enhancing the charge transport of organic functional materials through SWE approach appears to be a promising route towards water-tolerant OSC, OLED and OFET devices. In particular, this strategy presents a major step forward for advancing the field of organic electronics in which charge transport plays a role.

Received 25 April 2021; accepted 7 May 2021; published online 16 July 2021

1 Li S, Li CZ, Shi M, et al. New phase for organic solar cell research: Emergence of Y-series electron acceptors and their perspectives. ACS Energy Lett, 2020, 5: 1554-1567

2 Fukuda K, Yu K, Someya T. The future of flexible organic solar cells. Adv Energy Mater, 2020, 10: 2000765

3 Lee C, Lee S, Kim GU, et al. Recent advances, design guidelines, and prospects of all-polymer solar cells. Chem Rev, 2019, 119: 8028-8086

4 Guo J, Min J. A cost analysis of fully solution-processed ITO-free organic solar modules. Adv Energy Mater, 2019, 9: 1802521

5 Wang T, Sun R, Shi M, et al. Solution-processed polymer solar cells with over $17 \%$ efficiency enabled by an iridium complexation approach. Adv Energy Mater, 2020, 10: 2000590

6 Luo Z, Ma R, Liu T, et al. Fine-tuning energy levels via asymmetric end groups enables polymer solar cells with efficiencies over $17 \%$. Joule, 2020, 4: 1236-1247

7 Cui Y, Yao H, Zhang J, et al. Single-junction organic photovoltaic cells with approaching 18\% efficiency. Adv Mater, 2020, 32: 1908205
8 Yang W, Luo Z, Sun R, et al. Simultaneous enhanced efficiency and thermal stability in organic solar cells from a polymer acceptor additive. Nat Commun, 2020, 11: 1218

9 Yao H, Wang J, Xu Y, et al. Recent progress in chlorinated organic photovoltaic materials. Acc Chem Res, 2020, 53: 822-832

10 Zhao J, Li Y, Yang G, et al. Efficient organic solar cells processed from hydrocarbon solvents. Nat Energy, 2016, 1: 15027

11 Sun R, Wang T, Luo Z, et al. Achieving eco-compatible organic solar cells with efficiency $>16.5 \%$ based on an iridium complexincorporated polymer donor. Sol RRL, 2020, 4: 2000156

12 Liu Q, Jiang Y, Jin K, et al. $18 \%$ Efficiency organic solar cells. Sci Bull, 2020, 65: 272-275

13 Cheng P, Yang Y. Narrowing the band gap: The key to highperformance organic photovoltaics. Acc Chem Res, 2020, 53: $1218-1228$

14 Zheng Z, Yao H, Ye L, et al. PBDB-T and its derivatives: A family of polymer donors enables over $17 \%$ efficiency in organic photovoltaics. Mater Today, 2019, 35: 115-130

15 Wang W, Chen B, Jiao X, et al. A new small molecule donor for efficient and stable all small molecule organic solar cells. Org Electron, 2019, 70: 78-85

16 Wan X, Li C, Zhang M, et al. Acceptor-donor-acceptor type molecules for high performance organic photovoltaics-chemistry and mechanism. Chem Soc Rev, 2020, 49: 2828-2842

17 Li X, Huang G, Chen W, et al. Size effect of two-dimensional conjugated space in photovoltaic polymers' side chain: Balancing phase separation and charge transport. ACS Appl Mater Interfaces, 2020, 12: 16670-16678

18 Heumueller T, Mateker WR, Sachs-Quintana IT, et al. Reducing burn-in voltage loss in polymer solar cells by increasing the polymer crystallinity. Energy Environ Sci, 2014, 7: 2974-2980

19 Min J, Jiao X, Ata I, et al. Time-dependent morphology evolution of solution-processed small molecule solar cells during solvent vapor annealing. Adv Energy Mater, 2016, 6: 1502579

20 Han YW, Jeon SJ, Lee HS, et al. Evaporation-free nonfullerene flexible organic solar cell modules manufactured by an all-solution process. Adv Energy Mater, 2019, 9: 1902065

21 Zuo G, Linares M, Upreti T, et al. General rule for the energy of water-induced traps in organic semiconductors. Nat Mater, 2019, 18: $588-593$

22 Kotadiya NB, Mondal A, Blom PWM, et al. A window to trap-free charge transport in organic semiconducting thin films. Nat Mater, 2019, 18: 1182-1186

23 Nicolai HT, Kuik M, Wetzelaer GAH, et al. Unification of traplimited electron transport in semiconducting polymers. Nat Mater, 2012, 11: 882-887

24 Guo J, Wu Y, Sun R, et al. Suppressing photo-oxidation of nonfullerene acceptors and their blends in organic solar cells by exploring material design and employing friendly stabilizers. J Mater Chem A, 2019, 7: 25088-25101

25 Adams J, Salvador M, Lucera L, et al. Water ingress in encapsulated inverted organic solar cells: Correlating infrared imaging and photovoltaic performance. Adv Energy Mater, 2015, 5: 1501065

26 Scholz S, Kondakov D, Lüssem B, et al. Degradation mechanisms and reactions in organic light-emitting devices. Chem Rev, 2015, 115: 8449-8503

27 Nikolka M, Schweicher G, Armitage J, et al. Performance improvements in conjugated polymer devices by removal of waterinduced traps. Adv Mater, 2018, 30: 1801874 
28 Gomes HL, Stallinga P, Cölle M, et al. Electrical instabilities in organic semiconductors caused by trapped supercooled water. Appl Phys Lett, 2006, 88: 082101

29 Tsai MJ, Meng HF. Electron traps in organic light-emitting diodes. J Appl Phys, 2005, 97: 114502

30 Nikolka M, Broch K, Armitage J, et al. High-mobility, trap-free charge transport in conjugated polymer diodes. Nat Commun, 2019, 10: 2122

31 Nikolka M, Nasrallah I, Rose B, et al. High operational and environmental stability of high-mobility conjugated polymer fieldeffect transistors through the use of molecular additives. Nat Mater, 2017, 16: 356-362

32 Sun $\mathrm{R}, \mathrm{Wu} \mathrm{Q}, \mathrm{Guo} J$, et al. A layer-by-layer architecture for printable organic solar cells overcoming the scaling lag of module efficiency. Joule, 2020, 4: 407-419

33 Sun R, Deng D, Guo J, et al. Spontaneous open-circuit voltage gain of fully fabricated organic solar cells caused by elimination of interfacial energy disorder. Energy Environ Sci, 2019, 12: 2518-2528

34 Sun R, Guo J, Sun C, et al. A universal layer-by-layer solutionprocessing approach for efficient non-fullerene organic solar cells. Energy Environ Sci, 2019, 12: 384-395

35 Wang W, Wu Q, Sun R, et al. Controlling molecular mass of lowband-gap polymer acceptors for high-performance all-polymer solar cells. Joule, 2020, 4: 1070-1086

36 Min J, Güldal NS, Guo J, et al. Gaining further insight into the effects of thermal annealing and solvent vapor annealing on time morphological development and degradation in small molecule solar cells. J Mater Chem A, 2017, 5: 18101-18110

37 Gurney RS, Lidzey DG, Wang T. A review of non-fullerene polymer solar cells: From device physics to morphology control. Rep Prog Phys, 2019, 82: 036601

38 Zhao F, Wang C, Zhan X. Morphology control in organic solar cells. Adv Energy Mater, 2018, 8: 1703147

39 Huang Y, Kramer EJ, Heeger AJ, et al. Bulk heterojunction solar cells: Morphology and performance relationships. Chem Rev, 2014, 114: 7006-7043

40 Zhang M, Guo X, Ma W, et al. A large-bandgap conjugated polymer for versatile photovoltaic applications with high performance. Adv Mater, 2015, 27: 4655-4660

41 Yuan J, Zhang Y, Zhou L, et al. Single-junction organic solar cell with over $15 \%$ efficiency using fused-ring acceptor with electrondeficient core. Joule, 2019, 3: 1140-1151

42 Min J, Kwon OK, Cui C, et al. High performance all-small-molecule solar cells: Engineering the nanomorphology via processing additives. J Mater Chem A, 2016, 4: 14234-14240

43 Yu R, Yao H, Hong L, et al. Design and application of volatilizable solid additives in non-fullerene organic solar cells. Nat Commun, 2018, 9: 4645

44 Nicolai HT, Mandoc MM, Blom PWM. Electron traps in semiconducting polymers: Exponential versus Gaussian trap distribution. Phys Rev B, 2011, 83: 195204

45 Zuo G, Li Z, Andersson O, et al. Molecular doping and trap filling in organic semiconductor host-guest systems. J Phys Chem C, 2017, 121: 7767-7775

46 Mandoc MM, de Boer B, Paasch G, et al. Trap-limited electron transport in disordered semiconducting polymers. Phys Rev B, 2007, 75: 193202

47 Min J, Jiao X, Sgobba V, et al. High efficiency and stability small molecule solar cells developed by bulk microstructure fine-tuning. Nano Energy, 2016, 28: 241-249
48 Min J, Luponosov YN, Gasparini N, et al. Effects of alkyl terminal chains on morphology, charge generation, transport, and recombination mechanisms in solution-processed small molecule bulk heterojunction solar cells. Adv Energy Mater, 2015, 5: 1500386

49 Karki A, Vollbrecht J, Gillett AJ, et al. The role of bulk and interfacial morphology in charge generation, recombination, and extraction in non-fullerene acceptor organic solar cells. Energy Environ Sci, 2020, 13: 3679-3692

50 Vollbrecht J, Brus VV, Ko SJ, et al. Quantifying the nongeminate recombination dynamics in nonfullerene bulk heterojunction organic solar cells. Adv Energy Mater, 2019, 9: 1901438

51 Brus VV, Proctor CM, Ran NA, et al. Capacitance spectroscopy for quantifying recombination losses in nonfullerene small-molecule bulk heterojunction solar cells. Adv Energy Mater, 2016, 6: 1502250

52 Albrecht S, Tumbleston JR, Janietz S, et al. Quantifying charge extraction in organic solar cells: The case of fluorinated PCPDTBT. J Phys Chem Lett, 2014, 5: 1131-1138

53 Proctor CM, Kim C, Neher D, et al. Nongeminate recombination and charge transport limitations in diketopyrrolopyrrole-based solution-processed small molecule solar cells. Adv Funct Mater, 2013, 23: 3584-3594

54 Karki A, Vollbrecht J, Dixon AL, et al. Understanding the high performance of over $15 \%$ efficiency in single-junction bulk heterojunction organic solar cells. Adv Mater, 2019, 31: 1903868

55 Zhu W, Spencer AP, Mukherjee S, et al. Crystallography, morphology, electronic structure, and transport in non-fullerene/nonindacenodithienothiophene polymer: Y6 solar cells. J Am Chem Soc, 2020, 142: 14532-14547

56 Heiber MC, Okubo T, Ko SJ, et al. Measuring the competition between bimolecular charge recombination and charge transport in organic solar cells under operating conditions. Energy Environ Sci, 2018, 11: 3019-3032

57 Bartesaghi D, Pérez IDC, Kniepert J, et al. Competition between recombination and extraction of free charges determines the fill factor of organic solar cells. Nat Commun, 2015, 6: 1

58 Wang T, Sun R, Xu S, et al. A wide-bandgap D-A copolymer donor based on a chlorine substituted acceptor unit for high performance polymer solar cells. J Mater Chem A, 2019, 7: 14070-14078

59 Yang W, Guo J, Sun R, et al. Finely tuned cores in star-shaped zwitterionic molecules for interface engineering of high-performance polymer solar cells. Sol RRL, 2019, 3: 1900166

60 Sun R, Wu Y, Guo J, et al. High-efficiency all-small-molecule organic solar cells based on an organic molecule donor with an asymmetric thieno[2,3-f] benzofuran unit. Sci China Chem, 2020, 63: $1246-1255$

61 Wang $\mathrm{C}$, Zhang $\mathrm{X}, \mathrm{Hu} \mathrm{W}$. Organic photodiodes and phototransistors toward infrared detection: Materials, devices, and applications. Chem Soc Rev, 2020, 49: 653-670

62 Xiao X, Pan G, Li T, et al. Magnetic-field guided solvent vapor annealing for enhanced molecular alignment and carrier mobility of a semiconducting diketopyrrolopyrrole-based polymer. J Mater Chem C, 2020, 8: 4477-4485

Acknowledgements This work was supported by the National Natural Science Foundation of China (NSFC) (51773157 and 52061135206), and the Fundamental Research Funds for the Central Universities. The authors also thank the support of the opening project of Key Laboratory of Materials Processing and Mold and Beijing National Laboratory for 
Molecular Sciences (BNLMS201905). We thank Yihua Chen and Huanping Zhou for conducting the thermal admittance spectroscopy (TAS) measurements.

Author contributions Shi M and Min J conceived the ideas and coordinated the work. Shi M designed the experiments, performed the fabrication of solar cell devices and data analysis. Wang $\mathrm{T}$ contributed to the donor polymer materials. Wu Y contributed to the acceptor materials. Xie G conducted the OLED performance measurement. Pei D and Ye $\mathrm{L}$ conducted the fabrication of OFET devices and their performance measurement. Wang $\mathrm{H}$ and Wang $\mathrm{T}$ did the capacitance spectroscopy measurements. Sun $\mathrm{R}$ and $\mathrm{Wu} \mathrm{Q}$ did the atomic force microscopy measurements. Yang $\mathrm{W}$ and Wang $\mathrm{W}$ did the transient physics measurements. Shi M and Min J contributed to manuscript preparation, and Shi M supervised by Min J conceived and directed the project. All authors commented on the manuscript.

Conflict of interest The authors declare that they have no conflict of interest.

Supplementary information Supporting data are available in the online version of the paper.

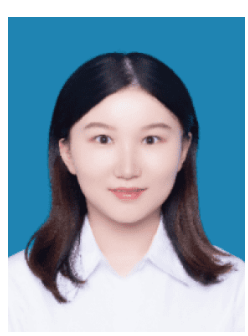

Mumin Shi received a BSc degree from Northwest Agriculture \& Forestry University in 2018. Now she is pursuing her MSc degree at the Institute for Advanced Studies, Wuhan University and her research focuses on the material and device stability in organic solar cells.

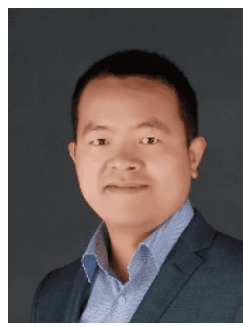

Jie Min is a full professor at the Institute for Advanced Studies, Wuhan University. During 2008-2011, he focused on the photovoltaic materials in the group of prof. Yongfang $\mathrm{Li}$ as a joint master. In 2015, he completed his PhD study in the Institute of Materials for Electronics and Energy Technology (i-MEET) at the Friedrich Alexander University Erlangen-Nuernberg under the supervision of prof. Christoph J. Brabec. From October 2015, he was a postdoctoral fellow in the group of Prof. Brabec in i-MEET. He joined Wuhan University in 2017. His major research interest is in the physics and chemistry of organic photovoltaic materials, and photovoltaic device physics and engineering.

\section{通过去除水致缺陷提升有机太阳能电池性能}

石沐民 ${ }^{1}$, 汪涛 ${ }^{1}$, 孙瑞 ${ }^{1}$, 吴强 ${ }^{1}$, 裴丹丹 ${ }^{2}$, 王茾 ${ }^{3}$, 杨文彦 ${ }^{1}$, 王伟 ${ }^{1}$, 吴遥，谢国华，王涛，叶龙，闵杰

摘要 由于水分子簇的电离能较低, 在有机共轭材料中, 水致缺陷 有可能在膜中分子间的空隙形成. 这就导致了较差的空穴和电子 传输能力, 使有机太阳能电池的光伏性能变差. 本工作研发了一种 溶剂-水蒸发(SWE)策略, 该策略可以有效去除光敏层中无处不在 的水诱导陷阱, 从而显著改善器件性能. 与未经处理的PM6:Y6二 元体系 $(15.83 \%)$ 相比, 使用这种SWE方法可实现该体系 $17.10 \%$ 的功 率转换效率和更好的器件光稳定性. 本文还揭示了该策略的独特 优势, 包括良好的电荷传输和提取特性以及在有机太阳能电池中 的良好通用性. 此外, 我们将该策略应用于有机发光二极管和有机 场效应晶体管, 证明了该SWE方法的普适性. 这一策略为推进有机 电子学领域的发展迈出了重要的一步. 